\title{
Simulasi Penjalaran Gelombang Tsunami di Sofifi- Tidore Kepulauan Maluku Utara sebagai Upaya Mitigasi Bencana
}

\author{
Mellisa Inggried Sumtakia*, Guntur Pasaua, Seni H. J. Tongkukuta \\ aJurusan Fisika, FMIPA, Unsrat, Manado
}

\begin{tabular}{l}
\hline K A T A K U N C I \\
\hline Tsunami, waktu tiba, winlTDB, \\
tinggi gelombang, Sofifi
\end{tabular}

\begin{abstract}
A B S T R A K
Telah dilakukan simulasi penjalaran gelombang tsunami di Sofifi - Tidore Kepulauan Maluku Utara untuk mengetahui waktu tiba dan tinggi gelombang tsunami yang menerjang pantai apabila gempa yang diikuti tsunami kembali terjadi. Simulasi menggunakan perangkat lunak WinITDB dengan memasukkan koordinat sumber tsunami, koordinat daerah yang akan diterjang tsunami, panjang patahan, lebar patahan dan deformasi dasar laut dari data gempa yang pernah menimbulkan tsunami. Hasil simulasi menunjukkan bahwa daerah Sofifi termasuk dalam klasifikasi tsunami yang cukup berbahaya dengan tinggi gelombang $0,5 \mathrm{~m} \leq \mathrm{H} \leq 1,5$ $\mathrm{m}$ dan waktu minimum gelombang tsunami mencapai pantai adalah 36 menit.
\end{abstract}

KEYW OR D S

Tsunami, arrival time, winlTDB, wave height, Sofifi

\begin{abstract}
A B S T R A C T
A simulation of tsunami wave transmission in Sofifi - Tidore archipelago, North Maluku has been done to know the arrival time and the height of tsunami wave that hits the coast if an earthquake that followed by tsunami reoccurs. The simulation is carried out using software WinITDB by inputting the coordinate of tsunami source, coordinate of the region that will be hit by the tsunami, the length and the width of the fracture, and the seafloor deformation from the data of earthquakes that ever triggered tsunamis. The result shows that Sofifi region is classified as fairly-dangerous with tsunami waveheight of $0,5 \mathrm{~m} \leq \mathrm{H} \leq 1,5 \mathrm{~m}$ and minimum time lapse for the tsunami wave to reach the coast is 36 minutes.
\end{abstract}

\section{TERSEDIA ONLINE}

1 Februari 2017

\section{Pendahuluan}

Kawasan Maluku Utara adalah kawasan yang didominasi oleh perairan, dengan perbandingan luas daratan dan laut adalah 1 : 3. Kawasan ini terdiri atas 353 pulau dengan luas kira-kira 32.000 $\mathrm{km}^{2}$, yang tersebar di atas perairan seluas 107.381 $\mathrm{km}^{2}$. Gugusan kepulauan di kawasan Maluku Utara terbentuk oleh relief-relief yang besar, palungpalung samudera, dan punggung pegunungan yang sangat mencolok saling bersambung silih berganti. Secara umum, struktur fisiografi kawasan Maluku Utara terbentuk dari zona pertemuan dua sistem bentang alam. Kedua sistem bentang alam tersebut adalah Sistem Bentang Alam Sangihe dan Sistem Bentang Alam Ternate, dengan batasnya adalah Cekungan Celebes di Barat dan Cekungan Halmahera di Timur.Zona benturan Laut Maluku merupakan bagian yang paling rumit.
Lempeng Laut Maluku, yaitu sebuah lempeng benua kecil mengalami tumbukan ke Palung Sangihe di bawah busur Sangihe di Barat dan kearah Timur di bawah Halmahera, sedangkan di sebelah selatannya terikat oleh Patahan Sorong.Busur Halmahera bagian dalam yang bersifat vulkanis berkembang di sepanjang pantai barat Halmahera dan menghasilkan pulau-pulau lautan yang bersifat vulkanis, antara lain adalah: Ternate, Tidore, Makian dan Moti. Pulau Mare terbentuk dari material vulkanis yang terangkat, sedangkan pulau Kayoa berasal dari terumbu karang yang terangkat. Mayu dan Tifure yang terletak di sepanjang gigir tengah Laut Maluku yang meninggi merupakan keping Melange aktif (Prasetya dkk., 2015).

Sofifi merupakan ibukota dari Provinsi Maluku Utara dan berada di Kecamatan Oba Utara,

*Corresponding author: Jurusan Fisika FMIPA UNSRAT, Jl. Kampus Unsrat, Manado, Indonesia 95115; Email address: inggriedsumtaki@gmail.com 
Kabupaten Tidore Kepulauan yangmemiliki jumlah penduduk 14.205 jiwa dengan kepadatan penduduknya 37,77 jiwa/ $\mathrm{km}^{2}$. Topografi pantai landai dan terhalang oleh pulau Ternate dan Tidore. Untuk itu, sangat dibutuhkan informasi mengenai daerah Sofifi yang berpotensi diterjang tsunami, berapa lama waktu tiba tsunami dan berapa ketinggian yang akan dicapai gelombang tsunami. Studi Simulasi Penjalaran Gelombang Tsunami menjadi jawaban akan kebutuhan masyarakat dan pemerintah dalam mendapatkan informasi tentang tsunami.

\section{Gempabumi dan Tsunami}

Gempabumi merupakan hentakan besar yang terjadi sekaligus akibat penimbunan energi elastik atau strain dalam waktu yang lama secara kontinu akibat dari pergerakan lempeng tektonik.

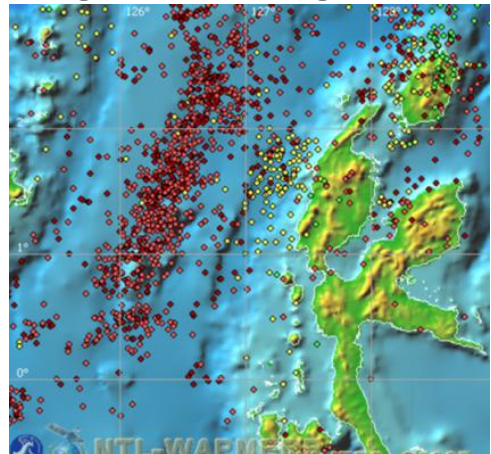

Gambar 1. Peta Seismisitas Maluku Utara

\section{Tsunami}

Tsunami adalah gelombang besar yang diakibatkan oleh gempa dengan episenternya terletak di laut dan tinggi gelombang dapat mencapai 30 meter. Gelombang tsunami dapat menyapu seluruh yang ada disekitar pantai. Gambar 2 menunjukkan tsunami yang diawali dengan patahan di dasar laut. Patahan tersebut membuat air laut menjadi surut dan setelah itu dengan energi yang terkumpul akan membuat air laut mengalir kedarat dengan kecepatan yang bisa mencapai 500 km/jam. Patahan dapat mencapai kedalaman 15 meter sepanjang ratusan kilometer (Taringan 2005).

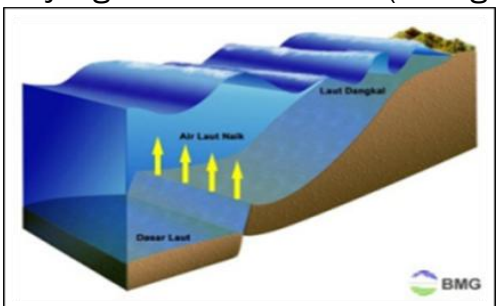

Gambar 2. Proses terjadinya tsunami(BMG, 2005)

Well dan Coppersmith (1994) menentukan panjang patahan, lebar patahan, dan pergeseran dasar laut yang didasarkan pada besar magnitudo yang diketahui untuk kondisi patahan naik sebagai berikut :

$$
\begin{aligned}
& \log (L)=0,63 M-2,86 \\
& \log (W)=0,41 M-1,61 \\
& \log (D)=0,29 M-1,84
\end{aligned}
$$

$M$ adalah Magnitudo, $L$ adalah panjang patahan $(\mathrm{km}), W$ adalah lebar patahan $(\mathrm{km})$, dan $D$ adalah deformasi dasar laut $(\mathrm{m})$.

\section{Waktu dan Kecepatan Pergerakan Tsunami}

Berdasarkan teori yang diperoleh dari Thorne Lay dan Terry C.Wallace (Modern Global Seismology, hal. 149), kecepatan tsunami merupakan akar dari hasil perkalian antara percepatan gravitasi dan kedalaman laut.

dengan :

$$
v=\sqrt{g h}
$$

$\mathrm{v}=$ kecepatan gelombang tsunami $(\mathrm{m} / \mathrm{s})$.

$\mathrm{g}=$ percepatan gravitasi bumi $\left(9,8 \mathrm{~m} / \mathrm{s}^{2}\right)$.

$\mathrm{h}=$ kedalaman laut $(\mathrm{m})$.

Kecepatan tsunami berbeda untuk setiap kedalaman laut yang berbeda, kecepatan tsunami yang menuju pantai berubah dari $v(x)_{0,} v(x)_{1}, v(x)_{2}, v(x)_{3,} \ldots . v(x)_{n}$. Dengan demikian, didapatkan hubungan antara kecepatan terhadap jarak. Untuk memudahkan perhitungan, kecepatangelombang tsunami diwakili oleh kecepatan rata-ratanya, melalui perhitungan denganrumus (Sutrisno, 2006):

$$
\bar{v}=\frac{\int_{0}^{x} v(x) d x}{x}
$$

Perhitungan di atas dapat disederhanakan menjadi :

$$
\begin{aligned}
\bar{v} & =\frac{v(x)_{1} \cdot \Delta x+v(x)_{2} \cdot \Delta x+v(x)_{3} \cdot \Delta x+\cdots+v(x)_{n} \cdot \Delta x}{n-1} \\
& =\left(v_{1}+v_{2}+v_{3}+\cdots+v_{n}\right) \frac{\Delta x}{n-1}=\frac{\sum v_{x}}{n-1}
\end{aligned}
$$

Waktu tiba gelombang tsunami dihitung dengan memperhatikan perubahan kedalaman laut yang dilewati gelombang tsunami. Semakin mendekati pantai maka kedalaman laut semakin dangkal. Dengan kecepatan rata-ratagelombang tsunami yang diperoleh, waktu penjalarangelombang tsunami dapat diketahui melalui perhitungan dengan rumus :

$$
t=\frac{x}{\bar{v}}
$$

dimana :

$\mathrm{t}=$ waktu tempuh $(\mathrm{sec})$.

$\mathrm{x}=$ jarak dari episenter ke lokasi pengamatan $(\mathrm{m})$.

$\bar{v}=$ kecepatan rata-rata $(\mathrm{m} / \mathrm{s})$.

(Sutrisno, 2006)

\section{Energi dan Tinggi Gelombang Tsunami}

Besar energi air yang terdorong oleh patahan naik diperoleh dengan menggunakan model "waterberg". Ketika terjadi patahan naik, air yang berada di atas patahan tersebut terdorong sehingga volume air menjadi sama dengan volume patahan $(\mathrm{V}=\mathrm{LWD})$. Massa air yang terangkat dari titik kesetimbangannya yaitu $\mathrm{m}=\rho \mathrm{V}$ atau $\mathrm{m}=\rho L W D$. Energi yang terkandung dalam massa air yang terdorong karena patahan ini adalah energi potensial. Apabila setiap partikel air yang terdorong oleh patahan naik memiliki tinggi rata - rata sebesar $\frac{D}{2}$ maka besar energi potensialnya adalah: 


$$
E=m g \frac{1}{2} D=\frac{1}{2} \rho L W g D^{2}
$$

Tinggi gelombang tsunami terbentuk sama dengan besar deformasi laut (D). Zein (2005) mengatakan hasil kali antara kecepatan gelombang tsunami, energi gelombang tsunami dan jarak arah rambat gelombang tsunami untuk setiap kedalaman adalah konstan.

dengan :

$$
v\left(\frac{1}{2} \rho L W g H^{2}\right) b=\text { constan }
$$

$\mathrm{v}=$ kecepatan tsunami $(\mathrm{m} / \mathrm{s})$

$\rho=$ massa jenis air $\left(\mathrm{kg} / \mathrm{m}^{3}\right)$

$\mathrm{L}=$ panjang patahan $(\mathrm{m})$

$\mathrm{W}=$ lebar patahan $(\mathrm{m})$

$\mathrm{H}=$ tinggi tsunami $(\mathrm{m})$

$\mathrm{b}=$ jarak arah rambat gelombang $(\mathrm{m})$

Energi yang dirambatkan dari sumber tsunami hingga ke pantai adalah konstan, sehingga pada kedalaman $\mathrm{n}-1$ dan $\mathrm{n}$ berlaku hubungan:

$$
c(v H b)_{n-1}=c(v H b)_{n}
$$

dengan $c$ adalah konstan.

Dari persamaan diatas dapat disimpulkan, tinggi gelombang tsunami (Bryant, 2008)

dimana :

$$
H_{n}=\sqrt{\frac{v_{n-1}}{v_{n}}} \sqrt{\frac{b_{n-1}}{b_{n}}} H_{n-1}
$$

$$
\begin{array}{llll}
\mathrm{n} & =\text { bernilai } 1,2,3 \text {, sampai } \mathrm{n} & \\
H_{n} & =\text { tinggi gelombang tsunami pada } \\
& \text { kedalaman } \mathrm{n}(\mathrm{m}) & \\
H_{n-1} & =\text { tinggi gelombang tsunami } & \text { pada } \\
& \text { kedalaman } \mathrm{n}-1(\mathrm{~m}) \\
v_{n-1} & =\text { kecepatan tsunami pada } \mathrm{n}-1(\mathrm{~m} / \mathrm{s}) \\
v_{n} & =\text { kecepatan tsunami pada kedalaman } \mathrm{n} \\
& (\mathrm{m} / \mathrm{s}) \\
b_{n-1} & =\text { jarak arah rambat gelombang pada } \\
& \begin{array}{l}
\text { kedalaman } \mathrm{n}-1(\mathrm{~m}) \\
b_{n}
\end{array} & =\text { jarak arah rambat gelombang pada } \\
& \text { kedalaman } \mathrm{n}(\mathrm{m})
\end{array}
$$

Latief, dkk (2006) menerangkan bahwa tingkat bahaya tsunami ditentukan berdasarkan tinggi gelombang tsunami di pantai.

Tabel 1.Klasifikasi Bahaya Tsunami Berdasarkan Tinggi Gelombang

\begin{tabular}{|c|c|}
\hline $\begin{array}{c}\text { Tinggi Gelombang } \\
\text { Tsunami }\end{array}$ & Klasifikasi \\
\hline $\mathrm{H} \geq 3 \mathrm{~m}$ & Sangat Bahaya \\
\hline $1,5 \mathrm{~m} \leq \mathrm{H}<3 \mathrm{~m}$ & Bahaya \\
\hline $0,5 \mathrm{~m} \leq \mathrm{H}<1,5 \mathrm{~m}$ & Cukup Bahaya \\
\hline $\mathrm{H}<0,5 \mathrm{~m}$ & Tidak Bahaya \\
\hline
\end{tabular}

Sumber: Rahmawan dkk (2012)

\section{MetodePenelitian}

Data yang digunakan dalam penelitian ini adalah data gempa yang pernah terjadi dan yang berpusat di Laut Maluku periode tahun 1890 sampai tahun 2015, dengan kedalaman $\leq 60 \mathrm{~km}$ dan magnitude $\geq 6,5 \mathrm{Mw}$. Data historis diambil darikatalog USGS. Daerah yang akan diteliti adalah wilayah Sofifi - Tidore Kepulauan, Maluku Utara yang terletak pada 0॰44'13.32"LU-044'14.65"LU dan 127033'31.53" BT - 127050'04.02 BT. Penelitian ini dilakukan dengan menggunakan komputer/laptop windows XP dan software winITDB.

Penelitian diawali dengan memilih lokasi yang padat penduduk di daerah Sofifi - Tidore Kepulauan. Lokasi yang dipilih akan diplotkan sebagai titik tempat yang akan diterjang tsunami dalam software WinITDB, kemudian mengambil data historis gempabumi dari USGS mulai tahun 1890 - 2015 dan memilih data gempa yang menyebabkan tsunami. Selanjutnya melakukan perhitungan panjang patahan, lebar patahan dan deformasi dasar laut yang disebabkan gempabumi dengan menggunakan rumus dari Well dan Coopersmith seperti pada persamaan 2.1a, 2.1b,dan 2.1c. Melakukan simulasi dengan menggunakan software WinITDB untuk mendapatkan tinggi maksimum $\left(H_{\max }\right)$ tsunami dan waktu tiba (arrival time) tsunami dengan memasukan posisi lintang sumber tsunami, posisi bujur sumber tsunami, posisi lintang daerah yang akan diterjang tsunami, posisi bujur daerah yang akan diterjang tsunami, panjang patahan, lebar patahan, deformasi dasar laut, waktu maksimum penjalaran tsunami.

\section{Hasil dan Pembahasan Data Historis Gempa}

Berdasarkan data historis gempa dari USGS periode tahun 1890 sampai dengan tahun 2015, terdapat 24 kejadian gempabumi yang berpusat di Laut Maluku dan berada pada kedalaman $\leq 60 \mathrm{~km}$ dan magnitudo $\geq 6,5$ Mw.Dari data historis gempabumi yang ada, kemudian disajikan dalam bentuk peta penyebaran gempa dengan menggunakan software WinITDB.

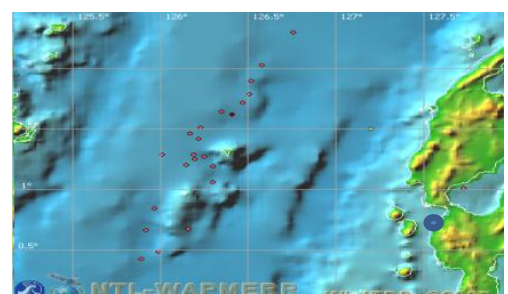

Gambar 3.Sebaran Kejadian Gempabumi yang berpusat di Laut Maluku berdasarkan Data Historis (Sumber : USGS)

Dari 24 data gempa yang telah ditampilkan, ada 3 kejadian gempabumi yang menyebabkan tsunami. Ketiga data ini digunakan untuk menghitung panjang patahan (L), lebar patahan (W), dan deformasi (pergeseran) dasar laut. Rumus yang digunakan adalah rumus Wells dan Coppersmith (1994) yang didasarkan dalam kondisi patahan naik seperti pada persamaan (2.1a), (2.1b), (2.1c). Untuk satuan magnitudo gempabumi yang dipakai adalah Mw (Magnitudo Momen).

\section{Simulasi Penjalaran Gelombang}

Untuk mengetahui potensi tsunami di wilayah Sofifi, dilakukan simulasi dengan menggunakan software WinITDB. Hasil simulasi ini berupa grafik 
tinggi dan waktu tiba gelombang tsunami di daerah yang akan diterjang tsunami.

Simulasi waktu tiba gelombang tsunami dan tinggi maksimum gelombang tsunami diterapkan pada tiga lokasi pusat gempabumi yang berada pada Laut Maluku, yang menurut data historis di tempat itu adalah pusat gempabumi yang pernah menimbulkan tsunami.

Hasil simulasi dibahas berdasarkan 3 kejadian gempa yaitu Kejadian Gempa 1, Kejadian Gempa 2, dan Kejadian Gempa 3. Simulasi penjalaran gelombang dari masing - masing kejadian dapat dilihat pada gambar 4, gambar 6 dan gambar 8, sedangkan untuk grafik hasil simulasi dari masing masing kejadian ditampilkan pada gambar 5, gambar 7 dan gambar 9 .

\section{Kejadian Gempa 1}

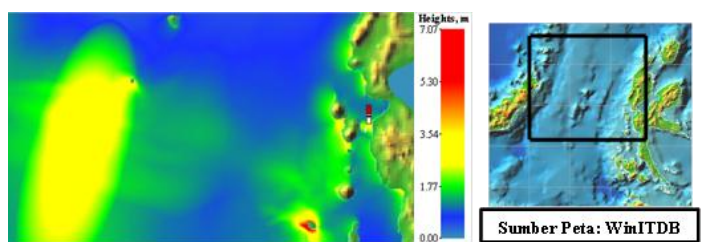

Gambar 4. Simulasi Penjalaran GelombangTsunami dari Kejadian Gempa 1

Kejadian Tsunami ini diakibatkan oleh gempabumi dengan magnitudo 7,7 Mw yang berada pada koordinat 0,493 LU dan 125,805 BT. Melalui perhitungan dengan rumus Wells dan Coopersmith didapatkan panjang patahannya $97,949 \mathrm{~km}$, lebar patahan $35,237 \mathrm{~km}$, dan deformasi dasar laut yaitu 2,5 meter. Tinggi maksimum gelombang tsunami akibat gempabumi dengan magnitudo $7,7 \mathrm{Mw}$ adalah 7,07 meter dan terjadi di daerah Kasturi. Untuk tinggi gelombang tsunami yang menerjang daerah Sofifi - Tidore Kepulauan adalah 1,25 meter.

Hasil simulasi dengan menggunakan software WinITDB untuk Kejadian Gempa 1 diberikan seperti pada gambar berikut.

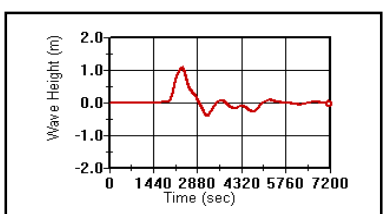

Gambar 5. Grafik Hasil Simulasi Kejadian Gempa 1

Gambar 5 menunjukkan bahwa gelombang tsunamitiba di pantai Sofifi pada menit ke - 38 atau pada detik ke - 2280 dengan tinggi gelombang tsunami 1,25 m. Setelah menit ke - 38, gelombang tsunami yang datang mempunyai tinggi yang semakin kecil.

\section{Kejadian Gempa 2}

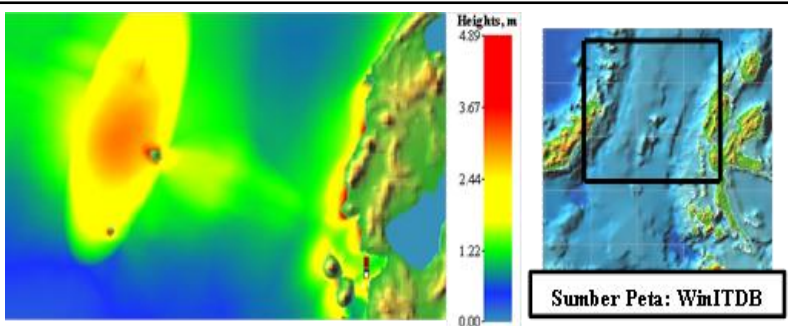

Gambar 6. Simulasi Penjalaran GelombangTsunami dari Kejadian Gempa 2

Pada kejadian tsunami dengan magnitudo gempa 7,6 Mw yang berada pada koordinat 1,420 LU dan 126,260 BT memiliki panjang patahan yaitu $84,723 \mathrm{~km}$, lebar patahannya $32,063 \mathrm{~km}$ dan pergeseran dasar laut $2,3 \mathrm{~m}$. Tinggi maksimum gelombang tsunami akibat gempabumi dengan magnitudo 7,6 Mw adalah 4,61 meter dan terjadi pada daerah Tataleka - Tobaru, Kampung Jawa dan Sarau. Pada daerah Sofifi - Tidore Kepulauan tinggi gelombangnya mencapai 1 meter.

Hasil simulasi Kejadian Gempa 2, diberikan seperti pada gambar berikut.

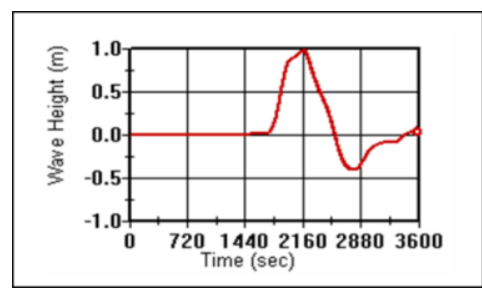

Gambar 7. Grafik Hasil Simulasi Kejadian Gempa 2

Gambar 7 menunjukkan bahwa gelombang tsunami tiba di pantai Sofifi pada menit ke - 36 (detik ke - 2160) dengan tinggi gelombang tsunami 1 meter. Setelah itu gelombang yang datang mempunyai tinggi yang lebih kecil.

\section{Kejadian Gempa 3}

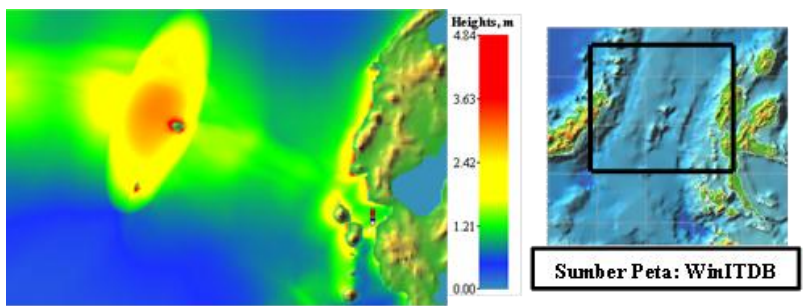

Gambar 8. Simulasi Penjalaran Gelombang Tsunamidari Kejadian Gempa 3

Kejadian tsunami dengan magnitudo gempa 7,5 Mw berada pada koordinat 1,514 LUdan126,234 BT. Panjang patahan yaitu $73,282 \mathrm{~km}$, lebar patahan 29,174 kmdan deformasi dasar laut 2,2 m serta memiliki tinggi gelombang maksimum yaitu 4,84 meter dan terjadi di Tataleka - Tobaru, Kampung Jawa dan Sarau. Gelombang tsunami yang menerjang daerah Sofifi - Tidore Kepulauan adalah 0,875 meter. Hasil simulasi dengan menggunakan software WinITDB untuk Kejadian Gempa 3 diberikan seperti pada gambar di bawah ini. 


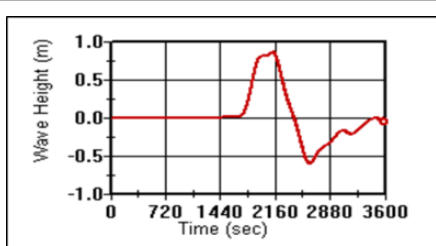

Gambar 9.Grafik Hasil Simulasi Kejadian Gempa 3

Gambar 9 menunjukkan bahwa gelombang tsunami tiba di pantai Sofifi berada pada menit ke 36 (detik - 2160) dengan tinggi gelombang 0,875 meter.Setelah menit ke - 36, gelombang tsunami yang datang mempunyai tinggi yang semakin kecil.

\section{Pembahasan}

Hasil analisis dari ketiga kejadian gempa yang telah disimulasikan, dapat dinyatakan bahwa daerah Sofifi - Tidore Kepulauan merupakan daerah yang memiliki ancaman yang cukup berbahaya terhadap tsunami karena memiliki tinggi gelombang tsunami lebih dari 0,5 meter dengan waktu tiba 36 sampai 38 menit. Untuk itu perlu adanya suatu rencana tindakan preventif dan mitigasi untuk mengurangi potensi resiko tsunami.

Ada beberapa hal yang harus dilakukan untuk mitigasi dan juga untuk pengembangan Sofifi sebagai ibukota Provinsi Maluku Utara, yaitu perencanaan lokasi (land management) dan pengaturan penempatan penduduk, membangun bangunan infrastruktur, melakukan usaha preventif dengan menata kembali aktifitas yang tinggi ke daerah yang lebih aman dengan mengembangkan mikrozonasi, melakukan upaya perbaikan lingkungan dengan maksud menyerap energi dari gelombang tsunami (misalnya dengan melakukan penanaman mangrove sepanjang pantai). Selain itu, mensosialisasikan dan melakukan training yang intensif bagi penduduk di daerah Sofifi yang rawan tsunami, serta membuat early warning system sepanjang daerah pantai Sofifi yang rawan tsunami

\footnotetext{
4. Kesimpulan

Berdasarkan hasil penelitian, dapat disimpulkan bahwa :
}

1. Waktu tiba minimum gelombang tsunami di Sofifi - Tidore Kepulauan yaitu pada menit ke 36 dan waktu maksimum yaitu pada menit ke 38.

2. Tinggi maksimum gelombang tsunami yang diakibatkan oleh gempabumi dengan episenter di Laut Maluku dari tahun 1890 - 2015 pada kedalaman $\leq 60 \mathrm{~km}$ dan magnitudo $\geq 6,5 \mathrm{Mw}$ pada daerah Sofifi - Tidore Kepulauan yaitu 1,25 meter.

3. Tsunami di daerah Sofifi - Tidore Kepulauan termasuk dalam klasifikasi tsunami yang cukup berbahaya, baik dari segi waktu maupun tinggi gelombangnya.

\section{Daftar Pustaka}

Bryant, E. 2008. Tsunami : Underrated Hazard. Springer and Praxis Publishing, London

Latief dkk, 2006, Pemodelan dan Pemetaan Rendaman Tsunami serta Kajian Resiko Bencana Tsunami Kota Padang, PPKPL, ITB. Bandung

Prasetya dkk, 2015. Peta Tektonik Maluku Utara. Universitas Negeri,Gorontalo.

Rahmawan dkk, 2012. Studi Potensi Bahaya Tsunami di Selatan Jawa. ITB. Bandung

Sutrisno. 2006. Penentuan Waktu Datang Gelombang Tsunami di Beberapa Kota PantaiSelatan Jawa Barat sebagai Informasi Penting dalam Usaha Penyelamatan Secara Preventif Menghadapi Bencana Tsunami. Universitas Islam Negeri Syarif Hidayatullah, Jakarta.

Tarigan, 2005, Pembelajaran dari Gempa Mexico, Liwa, Aceh dan Nias, Seminar DPRDSU 7Juli 2005, DPRD SU, Medan

ThorneL., Terry C.W., 1995. Modern Global Seismology. United Kingdom Edition,London.

Zein, M., T. 2005. Bencana Tsunami dan Gempabumi di Aceh, Diskusi Bencana Tsunami dan Gempabumi di Aceh, The Habibie Center16 Februari 2005, Jakarta 